ORIGINAL ARTICLE

\title{
Randomised trial of parental support for families with very preterm children: outcome at 5 years
}

\author{
S Johnson, W Ring, P Anderson, N Marlow
}

See end of article for authors' affiliations

Correspondence to: Dr N Marlow, Professor of Neonatal Medicine, Academic Division of Child Health, E Floor, East Block, University Hospital, Queen's Medical Centre, Nottingham NG7 2UH, UK; neil.marlow@ nottingham.ac.uk

Accepted 2 May 2005 Published Online First 17 May 2005

\begin{abstract}
Aims: To test the effectiveness of a home based developmental education intervention in improving outcome at 5 years for very preterm infants.

Methods: The Avon Premature Infant Project (APIP) is a randomised controlled trial in which the parents of 284 babies born $<33$ weeks gestational age received a developmental education programme, a social support intervention, or standard care. A term reference population was also recruited. This study reports outcomes at 5 years (mean age 58 months 15 days) for 187 (66\%) of these children without disability. Outcomes were assessed using the British Ability Scales II for cognitive development, the Movement $A B C$ for motor impairment, and the Child Behavior Checklist for behavioural problems.

Results: Preterm infants showed poorer cognitive performance than their term peers. Mean (SD) general conceptual ability (GCA) scores were: Portage 99.2 (15.7); parent adviser 100.3 (14.8); preterm control 101.1 (15.0); term reference 107.2 (13.4). There were no significant differences between preterm groups in GCA scores indicating no effect of either intervention. Similarly, there was no significant effect of intervention on behavioural or motor outcomes. Further analyses, in which outcome data were adjusted for social factors, did not reveal any differences between the three preterm groups or by subgroups classified by a range of perinatal variables.

Conclusion: The small advantage shown at 2 years of age is no longer detectable at 5 years. These results question the effectiveness of early intervention in enhancing cognitive, behavioural, and motor function at 5 years.
\end{abstract}

$P$ reterm birth and events that occur in the perinatal period may have adverse effects on a child's future development. ${ }^{12}$ Preterm children have well documented poorer cognitive, motor, and behavioural outcomes than their term peers, and these effects persist into adolescence and adulthood..$^{3-13}$ Not all preterm babies will have poor outcomes: the impact of prematurity and perinatal insult leads to an increased developmental vulnerability that may be mediated in part by environmental experience. ${ }^{14-17}$

There has been increasing interest in a range of early intervention programmes of developmental care and education for preterm children and their families. Studies of the efficacy of these interventions have shown modest improvements in short term cognitive and behavioural outcomes. ${ }^{18-20}$ However, such studies have generally lacked methodological rigour, being small single site studies or having focused on subsets of the population, ${ }^{21}$ and have rarely assessed outcomes long after the period of intervention has finished.

Other studies have investigated effects of interventions on both short and long term outcomes for more heterogeneous samples. In the Infant Health and Development Program $(\text { IHDP })^{22}$ - a multicentre randomised trial of early intervention from discharge to 3 years-children in the intervention group showed significantly better cognitive development scores than the control group at 2 and 3 years, with a larger effect size for the heavier infants (2001-2500 g); small differences were also noted in behavioural outcomes. However, these effects were not sustained after the period of intervention. At both 5 and 8 years there were no differences between intervention and control groups for cognitive or behavioural outcomes, although the heavier infants alone continued to show modest improvements in cognition. ${ }^{22-28}$ In contrast, other studies have found increasing beneficial effects several years after the intervention period..$^{29}{ }^{30}$ The results to date with regards the long term efficacy of such interventions are thus inconclusive.

These studies recruited relatively mature preterm infants and the IHDP combined early developmental education with family support services; it is thus difficult to disentangle the effects of developmental education alone from the effects of enhanced parental support on the gains observed in short term outcomes.

We investigated the effect of a two year home based developmental education programme for parents of very preterm babies, the Avon Premature Infant Project (APIP). ${ }^{31}$ At two years of age corrected for prematurity there were only small positive effects on cognitive outcome for those children whose families had received the intervention. However, after planned secondary analysis significant effects were seen among children without severe disability after correction for social confounders. Although early interventions are costly to apply, sustained effects would attenuate the need for remedial intervention at school age. Furthermore, the poor predictive value of infant developmental assessment for school age performance means that it is important to investigate whether these effects have persisted. In this study, we aimed to show the presence of persisting effects on cognitive, behavioural, and motor outcomes at 5 years for the children in the APIP study.

\section{METHODS}

\section{Participants}

A total of 284 babies born $<33$ weeks gestational age were recruited to the Avon Premature Infant Project (APIP) at birth and were randomised to one of three groups: a Portage group whose parents received a developmental education programme, a parent adviser group who received a parental support intervention, or a preterm control group who 


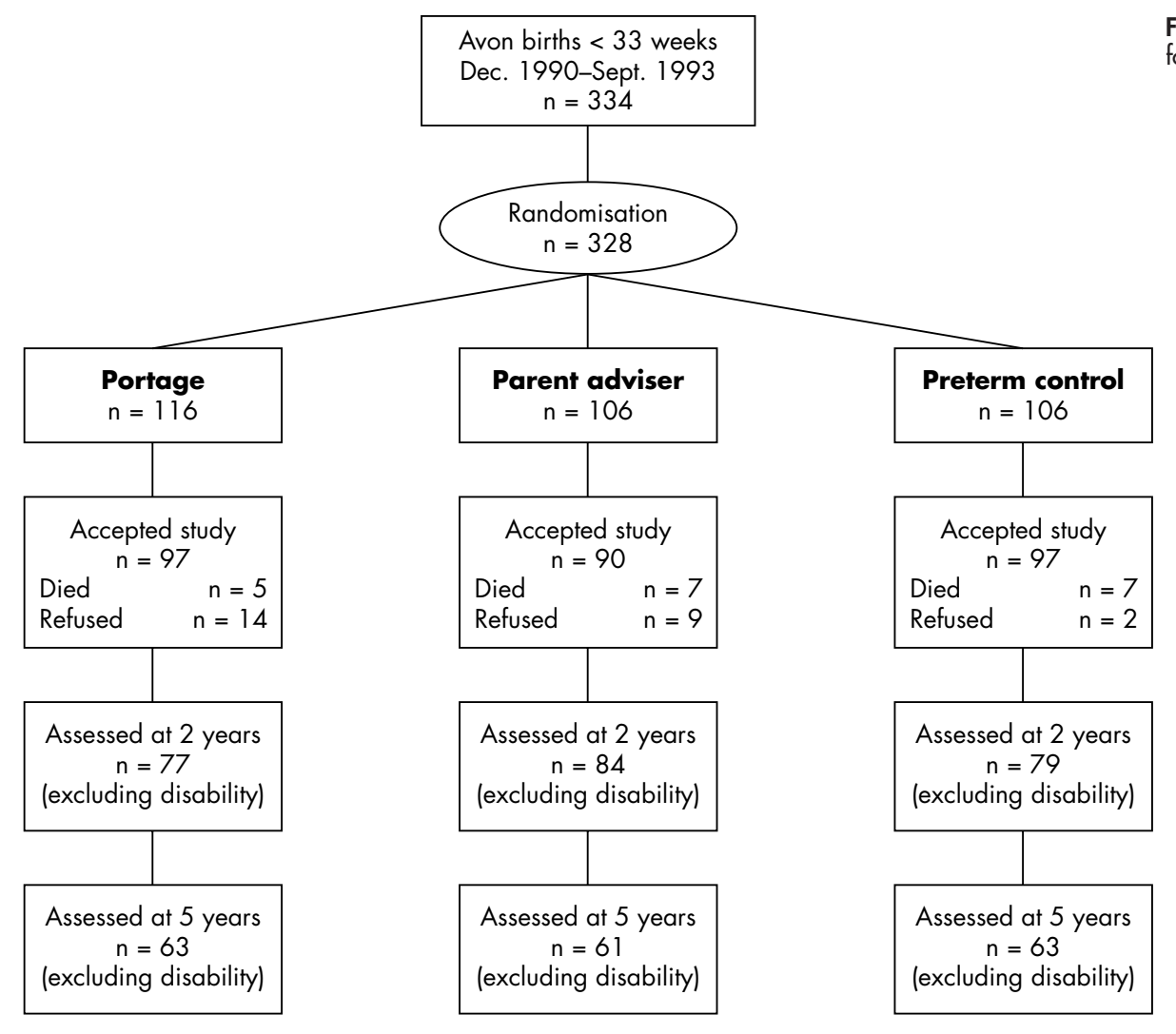

Figure 1 Patient flow and long term follow up at 5 years.

received standard care. Detailed descriptions of participant characteristics have been published previously. ${ }^{31}$ Children who survived to 5 years of age formed the sample for the present study. All were invited to participate, including families who had initially rejected the intervention following randomisation and who had defaulted on outcome assessments at 2 years. Children with known disabilities were examined (NM) and excluded if they were unable to complete the cognitive and motor tests because the study was not designed to determine benefit among these children. Analysis was on an intention to treat basis.

Of the 240 children without disability who were invited to participate, 179 (75\%) were evaluated for this study, together with a further eight children who had not been assessed at 2 years. Thus a total of 187 children without disability (66\% of those initially recruited) were assessed at 5 years (fig 1). These children did not differ from those without serious disability who were not assessed in terms of gestation at birth, birth weight, sex distribution, or distribution of intervention group (table 1). There was evidence of response bias, however, in that the children evaluated at 5 years had higher Griffiths' scores at 2 years and more advantageous social and demographic markers than those not assessed.

An additional 109 singleton babies were recruited at birth to a term reference group; of these, 87 children were evaluated at 2 years, 66 were reassessed at 5 years. Children were assessed at a mean age of 58 months 15 days (range 51-76 months).

\section{Interventions ${ }^{31}$}

The two intervention groups (Portage and parent adviser) were structured to be as similar as possible in number of intervention workers, visiting frequency, and supervision by a clinical psychologist. All interventions were mediated by nurses with either nursery nurse $(n=6)$ or state enrolled nurse $(n=2)$ qualifications and experience of the hospital care of small babies. All received basic training in child protection issues and in non-directive counselling skills.

\section{Developmental intervention: the Portage group}

Portage (London: NFER Nelson) is a widely available package that has been adapted for use in the UK. We used Portage for its original target population- children with developmental delay. The package has not been the subject of a previous randomised trial. The research team developed a programme of activities to introduce the parent to aspects of their child's development, which facilitated the introduction of Portage earlier. The detailed precision teaching, which involves a task analysis approach, was generalised for many of the children who were developing normally, within the Portage model. Throughout the course of the project, care was taken to maintain consistency of intervention. The four nurses received weekly structured supervision by a clinical psychologist and regular contact with the National Portage Association.

\section{Non-developmental intervention: the parent adviser group}

The primary focus of Portage is the developmental progress of the child, although parental support is provided as part of the delivery. We developed a second intervention with parental support as the main focus, based on the parent adviser scheme. $^{32}$ Training comprised a series of seminars and individual and group work, using a supportive counselling model. To isolate the effect of the developmental intervention further, the research nurses from the Portage group were also trained in this intervention. Ongoing supervision for the four parent adviser nurses was also supplied on a weekly basis by a clinical psychologist. 


\begin{tabular}{|c|c|c|c|c|c|}
\hline & \multicolumn{2}{|c|}{ Not seen at 5 years } & \multicolumn{2}{|c|}{ Seen at 5 years } & \multirow[b]{2}{*}{$\mathrm{p}$ value } \\
\hline & $\mathrm{n}$ & & $n$ & & \\
\hline Gestation at birth (med; IQR) & 86 & $30(29-31)$ & 187 & $30(29-32)$ & 0.66 \\
\hline Birth weight (g; med; IQR) & 86 & $1480(1090-1745)$ & 187 & $1440(1140-1700)$ & 0.48 \\
\hline Male sex (n (\%)) & 86 & $46(54 \%)$ & 187 & $112(60 \%)$ & 0.32 \\
\hline Portage group (n (\%)) & 86 & $33(38 \%)$ & 187 & $65(35 \%)$ & 0.56 \\
\hline Parent adviser group (n (\%)) & 86 & $31(36 \%)$ & 187 & 61 (33\%) & 0.58 \\
\hline$G Q$ at 2 years (mean (SD)) & 61 & $92(8.3)$ & 179 & $101(10.1)$ & $<0.001$ \\
\hline Maternal age $(y$; mean (SD)) & 73 & $25(5.1)$ & 179 & $26.9(4.8)$ & 0.004 \\
\hline Only child (n (\%)) & 78 & $31(40 \%)$ & 185 & $92(50 \%)$ & 0.005 \\
\hline Non-manual SES (n (\%)) & 77 & $13(17 \%)$ & 185 & $85(45 \%)$ & $<0.001$ \\
\hline Car use by mother (n (\%)) & 73 & $32(44 \%)$ & 177 & $121(68 \%)$ & $<0.001$ \\
\hline Single parent (n (\%)) & 78 & $19(22 \%)$ & 183 & $16(9 \%)$ & 0.004 \\
\hline
\end{tabular}

Intervention delivery

Both interventions began on discharge from the intensive care nurseries. Visiting was weekly for the first few months, reduced to 2-4 weekly for the next year, and then to monthly by the time disengagement occurred at 2 years, or earlier if requested by the parent. To a limited extent the frequency of visiting was tailored to suit the family. The visiting frequency and duration of each visit was similar for each group. The research nurse endeavoured to coordinate care with each family's health visitor. Following a referral to the community disability service, the research nurse liaised with the disability team to facilitate management. Regular outpatient visits occurred as part of the normal neonatal service. Both term and preterm children were examined by independent observers at 2 years who were blinded to study group. Disability and impairment were coded by one observer (NM) using standardised definitions.

\section{Procedure}

At $4 \frac{1}{2}-5$ years of age parents of surviving APIP children were contacted and asked to attend an appointment at a clinic in one of two local neonatal units. Prior to the appointment children with disability at 2 years were re-evaluated by a neonatal consultant to assess their ability to complete the outcome assessments at 5 years. At the study appointment children were assessed by a psychologist who was blind to the randomised group allocation of participants.

\section{Measures}

Cognitive development was assessed using the British Ability Scales 2nd Edition (BAS-II);3 motor impairment was assessed using the Movement $\mathrm{ABC}(\mathrm{M}-\mathrm{ABC}) ;^{34}$ and behavioural outcome was assessed using the Child Behavior Checklist (CBCL/4-18). ${ }^{35}$ Children were randomly assigned to commence testing with cognitive or motor tests.

Approval for the present follow up was granted by the local research ethics committee at United Bristol Healthcare NHS Trust and at Southmead Hospital NHS Trust. Data were encoded for computer analysis using SPSS for Windows (version 11.1). Statistical tests are described in the results section.

\section{RESULTS}

The original sample size was calculated to detect a 5-6 point difference in scores on the primary outcome measure of cognitive development. The present data were analysed using SPSS v1l.0 on an intention to treat basis.

\section{Cognitive development}

The BAS-II is designed to produce three subscale scores and an overall general conceptual ability (GCA) score; these are norm referenced scores with a mean of 100 (SD 15). The scores are shown in table 2 by study group.

Mean differences from the term control group are shown in fig 2. Although the Portage group achieved significantly lower GCA scores than their term peers (one way ANOVA, $F(3,240)=3.44 ; p<0.05)$, there were no significant differences between the three preterm groups. Thus children whose families received either the Portage or parent adviser programme did not show improved overall cognitive scores at 5 years. The direction of effect with the lowest scores in the Portage group is the reverse of the effect at 2 years.

One way ANOVAs computed for differences in subscale scores indicated significant differences after Bonferroni correction for multiple comparisons $(p<0.0125)$. However, although children in the parent adviser and preterm control groups performed significantly worse than those in the term reference group in spatial ability $(p=0.009)$ and verbal

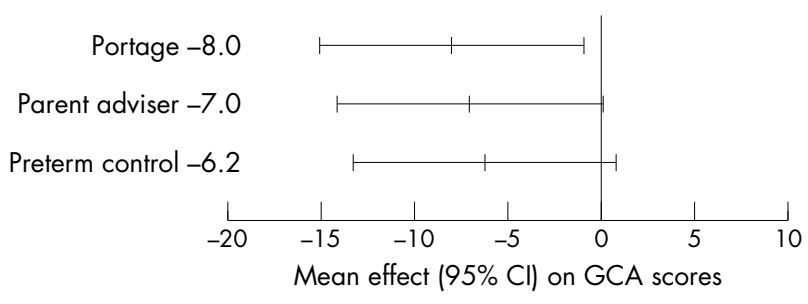

Figure 2 Mean differences $(95 \% \mathrm{Cl})$ in GCA scores for the Portage, parent adviser, and preterm control groups from the term reference group.

Table 2 Cognitive development at 5 years; mean (SEM) BAS-II subscale and GCA scores

\begin{tabular}{|c|c|c|c|c|c|c|c|c|c|c|c|c|}
\hline \multirow[b]{2}{*}{ BAS-II scores } & \multicolumn{3}{|c|}{ Portage } & \multicolumn{3}{|c|}{ Parent adviser } & \multicolumn{3}{|c|}{ Preterm control } & \multicolumn{3}{|c|}{ Term reference } \\
\hline & $n$ & Mean & SD & $n$ & Mean & SD & $n$ & Mean & SD & $n$ & Mean & SD \\
\hline Verbal reasoning & 67 & 101.8 & 13.2 & 64 & 102.0 & 13.5 & 67 & 99.3 & 18.0 & 63 & 107.7 & 12.8 \\
\hline Spatial ability & 62 & 99.8 & 16.9 & 61 & 96.4 & 16.0 & 63 & 99.1 & 14.1 & 57 & 105.8 & 13.9 \\
\hline Pictorial representation & 65 & 97.7 & 13.7 & 61 & 101.5 & 17.2 & 64 & 101.3 & 15.2 & 59 & 103.3 & 13.7 \\
\hline GCA & 63 & 99.2 & 15.7 & 61 & 100.3 & 14.8 & 63 & 101.1 & 15.0 & 57 & 107.2 & 13.4 \\
\hline
\end{tabular}


Table 3 Multiple regression analysis: independent effects of social and demographic factors at recruitment on BAS-II GCA scores at 5 years (preterm groups only)

\begin{tabular}{llll}
\hline Variable & $\begin{array}{l}\text { Size of effect } \\
\text { (B) }\end{array}$ & $\mathbf{9 5 \% ~ C l}$ & p value \\
\hline Both parents at home & +5.55 & $(-2.2$ to 13.3) & 0.157 \\
Non-manual SES & +8.42 & $(3.9$ to 13.0$)$ & 0.000 \\
Maternal age (years) & +0.28 & $(-0.2$ to 0.8$)$ & 0.242 \\
Number of siblings & -1.76 & $(-4.3$ to 0.8$)$ & 0.171 \\
Maternal use of a car & +5.18 & $(0.4$ to 10.0) & 0.035 \\
\hline *GCA points. & & & \\
\end{tabular}

reasoning $(p=0.010)$ respectively, there were no significant differences in performance between the three preterm groups. Thus the use of either the Portage or parent adviser programme did not improve performance on any subscale.

\section{Effect of social and demographic factors}

At 2 years, despite randomisation, there were differences between the preterm groups in the distribution of social and demographic factors, and five were independently associated with developmental scores: maternal age, non-manual parental occupations, use of a car, living with both parents, and number of siblings at recruitment. Using linear regression on the 2 year data, and after correction for these five variables, independent effects of both interventions compared to the control group were identified. Linear regression analyses were similarly conducted on the present data to determine whether these effects had persisted (table 3).

These factors accounted for $16 \%$ of the variance in GCA scores at 5 years, but only the mother's use of a car and employment in a non-manual occupation were independently associated with GCA scores in the preterm population. The direction of effect was the same as at 2 years. Within this regression model neither the Portage nor the parent adviser interventions were associated with enhanced GCA scores (fig 3).

Cognitive development: effect of perinatal variables Further planned secondary analysis at 2 years indicated significant associations between perinatal factors and developmental scores. These analyses were repeated using GCA scores, after adjustment for the effect of sociodemographic factors, in order to identify any subgroup effects (table 4).

The present analyses did not indicate advantage in GCA scores after adjustment for social factors for children in the Portage or parent adviser groups when categorised by any perinatal variable. Figure 4 shows the mean (95\% CI) differences from the preterm control group for each intervention group for the perinatal data items in table 4 . In contrast to the advantage shown by intervention at 2 years, there were non-significant trends for intervention to have had negative effects in these analyses and for children with birth weight $>1250$ g GCA scores were 2.8 points (95\% CI 0.2 to 5.5$)$ lower than preterm control children, reflecting a raw scores difference of 6.8 points (95\% CI 0.2 to 12.7 ).

\section{Motor impairment}

The Movement $\mathrm{ABC}(\mathrm{M}-\mathrm{ABC})$ is a standardised assessment of motor impairment yielding three subscale scores and a total motor impairment (TMI) score; median (IQR) subscale and TMI scores are shown in table 5.

A Kruskal-Wallis test indicated significant differences between the study groups $\left(\chi^{2}(3)=18.16, p=0.000\right)$. Post

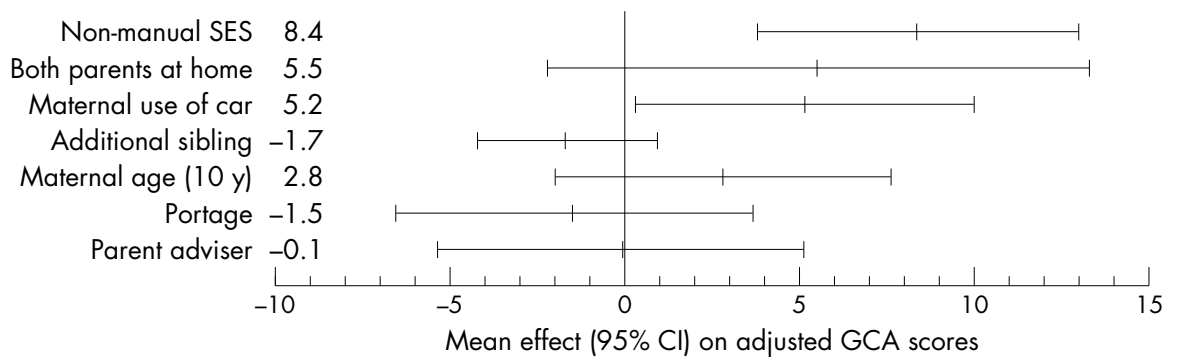

Figure 3 Effect size $(95 \% \mathrm{Cl})$ of social variables and interventions on BAS-II GCA scores at 5 years.

Table 4 GCA scores adjusted for effect of sociodemographic factors grouped by perinatal variables (preterm groups only)

\begin{tabular}{|c|c|c|c|c|c|c|}
\hline \multirow[b]{2}{*}{ Variable } & \multicolumn{2}{|c|}{ Portage } & \multicolumn{2}{|c|}{ Parent adviser } & \multicolumn{2}{|c|}{ Preterm control } \\
\hline & $n$ & Mean (SEM) & $n$ & Mean (SEM) & $n$ & Mean (SEM) \\
\hline Male & 39 & $99.7(1.0)$ & 34 & $99.3(1.2)$ & 33 & $103.0(1.0)$ \\
\hline \multicolumn{7}{|l|}{ Birth weight } \\
\hline$\leqslant 1250 \mathrm{~g}$ & 16 & $99.5(2.0)$ & 26 & $98.6(1.2)$ & 21 & $99.4(1.6)$ \\
\hline$>1250 \mathrm{~g}$ & 44 & $99.9(0.9)^{*}$ & 34 & $100.3(1.2)$ & 36 & $102.7(1.0)$ \\
\hline \multicolumn{7}{|l|}{ Gestation } \\
\hline$\leqslant 28$ weeks & 8 & $96.1(2.6)$ & 13 & 101.5 (1.9) & 13 & $100.6(1.9)$ \\
\hline$>28$ weeks & 52 & $100.3(0.9)$ & 47 & $99.1(0.9)$ & 44 & $101.8(1.0)$ \\
\hline Appropriate size for gestational age & 58 & $99.8(0.9)$ & 60 & $99.6(0.9)$ & 56 & $101.5(0.9)$ \\
\hline Normal ultrasound & 58 & $99.8(0.9)$ & 58 & $99.5(0.9)$ & 53 & $101.2(0.9)$ \\
\hline Any haemorrhage (PVH) & 8 & $103.0(2.7)$ & 4 & $96.9(4.6)$ & 5 & $99.3(3.7)$ \\
\hline Any periventricular leucomalacia & 6 & $98.5(3.9)$ & 4 & $94.0(1.5)$ & 5 & $98.4(4.4)$ \\
\hline Not ventilated & 18 & $100.4(1.3)$ & 18 & $98.6(1.6)$ & 19 & $100.2(1.5)$ \\
\hline Ventilated $\leqslant 7$ days & 49 & $100.0(0.9)$ & 41 & $99.6(1.2)$ & 41 & $101.7(1.1)$ \\
\hline Ventilated $>7$ days & 11 & $98.5(2.6)$ & 19 & $99.7(1.6)$ & 16 & $100.9(1.6)$ \\
\hline
\end{tabular}

$\mathrm{PVH}$, periventricular haemorrhage.

${ }^{*} \mathrm{p}<0.05$ for difference from preterm control group. 


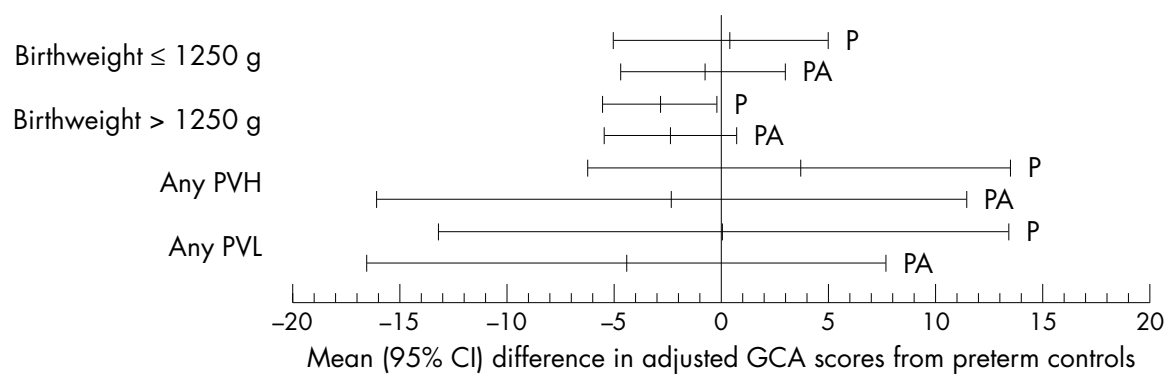

Figure 4 Mean differences $(95 \% \mathrm{Cl})$ in GCA scores from preterm controls for the Portage (P) and parent adviser (PA) groups categorised by perinatal variables.

hoc Mann-Whitney U tests revealed that although preterm children had higher scores than the term reference group $(p<0.01)$, there were no significant differences between the three preterm groups. Thus neither intervention improved motor development in comparison to standard care.

A cut off equivalent to the upper quartile of the term reference group scores defined motor impairment. In the preterm control group, $51 \%$ were classified as impaired compared to $52 \%$ of children in the Portage group (relative risk (RR) $1.03,95 \%$ CI 0.52 to 2.04 ) and $55 \%$ of children in the parent adviser group (RR 1.14, 95\% CI 0.57 to 2.26 ).

\section{Behavioural outcome}

The Child Behavior Checklist (CBCL) is a parent report questionnaire designed to assess problem behaviours from which are derived two main subscale scores and a total raw score. Table 6 details the median scores for each group.

A Kruskal-Wallis test indicated significant differences between the study groups $\left(\chi^{2}(3)=7.98, p<0.05\right)$. Post hoc Mann-Whitney U tests revealed that although the two intervention groups had significantly higher scores than the term reference group $(p<0.05)$, there were no differences between the three preterm groups. Thus the delivery of either intervention did not improve behavioural outcomes at 5 years.

CBCL subscale and total raw scores are converted to $\mathrm{T}$ scores for comparison with a normative sample. Using published cut offs, $11 \%$ of the preterm control group were considered to have problem behaviours within the clinical range ( $>98$ th centile), compared to $12 \%$ in the parent adviser group (RR 1.39, 95\% CI 0.60 to 3.19 ) and $17 \%$ of children in the Portage group (RR 1.48, 95\% CI 0.64 to 3.9); these differences were not significant.

\section{DISCUSSION}

The APIP Study was designed to determine the effectiveness of the Portage developmental education programme in enhancing the outcome of very preterm children. Predictably, at 5 years, performance of preterm children was poorer than that of their term peers on all outcomes assessed..$^{2-13}$ In keeping with outcomes at 2 years, primary analyses again revealed no beneficial effects of either intervention on the cognitive, motor, or behavioural function of preterm infants at 5 years. After planned secondary analyses at 2 years the authors identified improved cognition for children with birth weights $<1250 \mathrm{~g}$ and those with ultrasound abnormalities; by 5 years of age these effects were no longer detectable.

We were disappointed in the response rate for the current study. Analysis of the children seen identified no differences in important study or baseline perinatal variables with those not evaluated. However, there was significant response bias in that the children seen came from families with more markers of social advantage. Given the observation that interventions such as these may be more effective in the presence of social disadvantage, ${ }^{22}$ it is possible that we may have missed some advantage persisting in these groups. The results of Griffiths' scores at two years for the group not seen

Table 5 Motor impairment at 5 years; median (IQR) Movement $A B C$ subscale and total motor impairment scores

\begin{tabular}{|c|c|c|c|c|c|c|c|c|c|c|c|c|}
\hline \multirow[b]{2}{*}{ Movement $A B C$ scores } & \multicolumn{3}{|c|}{ Portage } & \multicolumn{3}{|c|}{ Parent adviser } & \multicolumn{3}{|c|}{ Preterm control } & \multicolumn{3}{|c|}{ Term reference } \\
\hline & $n$ & Median & IQR & $n$ & Median & IQR & $n$ & Median & IQR & $\mathrm{n}$ & Median & IQR \\
\hline Manual dexterity & 66 & 0.25 & $0.0-2.1$ & 64 & 1.75 & $0.0-3.0$ & 68 & 0.75 & $0.0-3.9$ & 61 & 0.0 & $0.0-0.0$ \\
\hline Ball skills & 66 & 0.0 & $0.0-2.0$ & 64 & 0.0 & $0.0-1.0$ & 68 & 0.0 & $0.0-2.0$ & 61 & 0.0 & $0.0-0.3$ \\
\hline Static and dynamic balance & 65 & 2.5 & $0.0-7.3$ & 64 & 2.0 & $0.5-5.0$ & 68 & 2.5 & $0.0-6.5$ & 61 & 0.5 & $0.0-3.5$ \\
\hline Total motor impairment & 65 & 4.5 & $1.0-10.8$ & 64 & 5.0 & $2.0-9.9$ & 68 & 4.5 & $1.1-9.4$ & 61 & 2.0 & $0.0-4.3$ \\
\hline
\end{tabular}

Table 6 Behaviour at 5 years; median (IQR) CBCL subscale and total raw scores

\begin{tabular}{|c|c|c|c|c|c|c|c|c|c|c|c|c|}
\hline \multirow[b]{2}{*}{ CBCL scores } & \multicolumn{3}{|c|}{ Portage } & \multicolumn{3}{|c|}{ Parent adviser } & \multicolumn{3}{|c|}{ Preterm control } & \multicolumn{3}{|c|}{ term reference } \\
\hline & $n$ & Median & IQR & $n$ & Median & IQR & $\mathbf{N}$ & Median & IQR & $n$ & Median & IQR \\
\hline Internalising subscale & 70 & 4 & $3-7$ & 63 & 4 & $2-8$ & 69 & 4 & $2-7$ & 66 & 3 & $2-5$ \\
\hline Externalising subscale & 70 & 10 & $5-13$ & 64 & 9 & $5-12$ & 69 & 7 & $4-14$ & 66 & 8 & $5-10$ \\
\hline Total score & 70 & 24 & $15-38$ & 65 & 23 & $15-36$ & 69 & 25 & $13-34$ & 66 & 18 & $13-28$ \\
\hline
\end{tabular}




\section{What is already known on this topic}

- While developmental interventions have shown modest improvements in preterm outcomes, particularly for heavier and more mature infants, the evidence regarding longer term sustained effects is inconclusive

- In the authors' randomised trial, developmental education (Portage) and enhanced parental support (parent adviser) for parents of very preterm ( $<33$ weeks) children both showed small positive effects on cognitive development at 2 years

at 5 years were slightly lower than for those evaluated, but there were no significant differences on raw or adjusted general quotient values when analysed by treatment group. This response bias we believe is also responsible for the slightly higher term comparison group scores than expected and apparently normal mean preterm scores.

Although developmental outcome did not appear to have improved by the end of the intervention, it is important to assess outcome later in childhood to identify any potentially later occurring or longer term effects on development, particularly given the poor predictive validity of infant assessments. We did not find any continued or new beneficial effect of either intervention 3 years after the period of delivery. This is consistent with previous studies of developmental interventions. ${ }^{29}{ }^{30}$ Results of such studies, together with the present findings, question the efficacy of early home based developmental interventions in improving the outcomes of preterm children beyond the period of support. It may thus be the case that the period of delivery of interventions tested to date needs to be sustained throughout early childhood and up to school entry for any effects of early developmental education to be maintained in later childhood and evidenced in early scholastic attainment.

The success of previous studies showing beneficial effects of intervention up to 3 years have been attributed to a combined programme of enhanced social support and targeted developmental education. The present study, in which we distinguished between these aspects of home based parental support, did not provide evidence that developmental education is any more beneficial than the provision of parental support alone. In future studies it might therefore be profitable to combine these elements in global individualised family intervention programmes, although careful economic evaluation, not undertaken here, will be required.

In addition, previous studies have enrolled heavier or more mature infants; IHDP investigators found the greatest effect of intervention for infants of heavier birth weights (2001$2500 \mathrm{~g}){ }^{24-28}$ Thus the efficacy of developmental interventions with very preterm infants has not been directly investigated. The utility of such interventions with very low birth weight infants is suggested by IHDP investigators who, in comparison with our secondary analyses at 2 years, found a significant reduction in behaviour problems and a trend to improved cognition at 3 years for extremely low birth weight babies after adjustment for infant and social characteristics, and after excluding those with severe disability. ${ }^{36}$ However, these effects were not maintained past the period of intervention delivery in either study. The present results, indicating no benefit of intervention targeted directly at such a sample, thus suggest that more refined programmes may be required to adequately fulfil the longer term needs of these families.

\section{What this study adds}

- Developmental advantages found at 2 years are lost by 5 years

- The subgroup effects found at 2 years are no longer present at 5 years

The administration of both intervention programmes in the present study commenced on discharge from the neonatal unit; for some families this may have been some 2-3 months after birth, with even greater periods of admission for babies born extremely preterm and those with a more complicated neonatal course. It is possible that intervention programmes for very preterm infants, commenced as soon as possible after birth while the baby is in the care of the neonatal unit, may have a greater impact on early development and be more effective in enhancing both short and longer term outcomes. Indeed, feedback provided by the research nurses delivering the interventions in the APIP study, and subsequent pilot work carried out to further develop the Portage programme for families with young very preterm babies, ${ }^{37}$ indicated that the parenting patterns they encountered had already been established by the time the intervention commenced; parents also expressed the opinion that the interventions were provided too late for real benefits to ensue. Developmental intervention programmes commenced during admission, and thus before anxiety and uncertainty regarding their parental role and inappropriate patterns of parental behaviour have become established, ${ }^{38}{ }^{39}$ but none have been evaluated in a prospective trial to date.

Effective developmental interventions with persisting long term effects are thus still required. Prevention of the cognitive disadvantage associated with very preterm birth remains one of the more elusive goals of modern perinatal care.

\section{ACKNOWLEDGEMENTS}

The authors wish to thank the original APIP Study team and all the parents and children who kindly took part in the study.

\section{Authors' affiliations}

S Johnson, Division of Child Health, University of Nottingham, UK W Ring, P Anderson, Division of Child Health, University of Bristol, UK N Marlow, Institute of Neuroscience, University of Nottingham, UK

Funding: this study was funded by an Action Medical Research Grant to Professor Neil Marlow

Competing interests: none

\section{REFERENCES}

1 Hack M, Fanaroff AA. Outcomes of children of extremely low birthweight and gestational age in the 1990s. Early Hum Dev 1999;53:193-218.

2 Marlow N. Neurocognitive outcome after very preterm birth. Arch Dis Child Fetal Neonatal Ed 2004;89:F224-8.

3 Bhutta AT, Cleves MA, Casey PH, et al. Cognitive and behavioral outcomes of school-aged children who were born preterm: a meta-analysis. JAMA 2002;288:728-37.

4 Botting N, Powls A, Cooke RWI, et al. Attention deficit hyperactivity disorders and other psychiatric outcomes in very low birthweight children at 12 years. J Child Psychol Psychiatry 1997;38:931-41.

5 Botting N, Powls A, Cooke RWl, et al. Cognitive and educational outcome of very-low-birthweight children in early adolescence. Dev Med Child Neurol 1998;40:652-60.

6 Briscoe J, Gathercole SE, Marlow N. Short-term memory and language outcomes after extreme prematurity at birth. J Speech Lang Hear Res 1998;41:654-66

7 Briscoe J, Gathercole SE, Marlow N. Everyday memory and cognitive ability in children born very prematurely. J Child Psychol Psychiatry 2001;42:749-54. 
8 Cooke RWI, Foulder-Hughes L. Growth impairment in the very preterm and cognitive and motor performance at 7 years. Arch Dis Child 2003;88:482-7 9 Hille ETM, den Ouden AL, Saigal S, et al. Behavioural problems in children who weigh $1000 \mathrm{~g}$ or less at birth in four countries. Lancet 2001:357:1641-3.

10 Johnson A, Bowler U, Yudkin P, et al. Health and school performance of teenagers born before 29 weeks gestation. Arch Dis Child Fetal Neonatal Ed 2003;88:F190-8.

11 Luoma L, Herrgard E, Martikainen A, et al. Speech and language development of children born at $\leqslant 32$ weeks' gestation: a 5 -year prospective follow-up study. Dev Med Child Neurol 1998;40:380-7.

12 Marlow N, Roberts BL. Motor skills in extremely low birthweight children at the age of 6 years. Arch Dis Child 1989;64:839-47.

13 Wolke D, Meyer R. Cognitive status, language attainment, and prereading skills of 6-year-old very preterm children and their peers: the Bavarian Longitudinal Study. Dev Med Child Neurol 1999;41:94-109.

14 Censullo M. Developmental delay in healthy premature infants at age two years: implications for early intervention. Dev Behav Pediatr 1994; 15:99-104.

15 Shonkoff JP, Marshall PC. The biology of developmental vulnerability. In: Shonkoff JP, Meisels SJ, eds. Handbook of early intervention. Cambridge, UK Cambridge University Press, 2000:35-53

16 Shonkoff JP, Meisels SJ. Handbook of early childhood intervention. Cambridge, UK: Cambridge University Press, 2000

17 Werner EE. Overcoming the odds. Dev Behav Pediatr 1994;15:131-6.

18 Bao X, Sun S, Wei S. Early intervention promotes intellectual development of premature infants: a preliminary report. Chin Med J 1999;116:520-3.

19 Resnick MB, Armstrong S, Carter RL. Developmental intervention program for high-risk premature infants: effects on development and parent-infant interactions. Dev Behav Pediatr 1988;9:73-8.

20 McCarton CM, Wallace IF, Bennett FC. Preventive interventions with low birth weight premature infants: an evaluation of their success. Semin Perinatol 1995; 19:330-40

21 Symington A, Pinelli J. Developmental care for promoting development and preventing morbidity in preterm infants (Cochrane Review). In: The Cochrane Library, 2. Oxford: Update Software, 2003.

22 Gross RT, Spiker D, Haynes CW. Helping low birth weight premature babies. Palo Alto, CA: Stanford University Press, 1997

23 Brooks-Gunn J, McCarton CM, Casey PH, et al. Early intervention in low birth-weight premature infants: results through age 5 from the Infant Health and Development Project. JAMA 1994;272:1257-62.

24 Brooks-Gunn J, Liaw F, Klebanov PK. Effects of early intervention on cognitive function of low birth weight preterm infants. J Pediatr 1992;120:350-9.
25 McCarton CM, Brooks-Gunn J, Wallace IF, et al. Results at age 8 years of early intervention for low-birth-weight premature infants: The Infant Health and Development Program. JAMA 1997;277:126-32.

26 McCormick MC, McCarton C, Brooks-Gunn J, et al. The Infant Health and Development Program: interim summary. Dev Behav Pediatr 1998; 19:359-70.

27 McCormick MC, McCarton C, Tonascia J, et al. Early educational intervention for very low birthweight infants: results from the Infant Health and Development Program. J Pediatr 1993; 123:527-33.

28 McCarton C. Behavioral outcomes in low birth weight infants. Pediatrics 1998;105:1293-7.

29 Achenbach TM, Howell CT, Aoki MF, et al. Nine year outcome of the Vermont program for low birthweight infants. Pediatrics 1993;91:45-55.

30 Sajaniemi N, Makela J, Salokorpi T, et al. Cognitive performance and attachment patterns at four years of age in extremely low birth weight infants after early intervention. Eur Child Adolesc Psychiatry 2001;10:122-9.

31 Avon Premature Infant Project. Randomised trial of parental support for families with very preterm children. Arch Dis Child Fetal Neonatal Ed 1998;79:F4-11.

32 Davis H, Rushton R. Counselling and supporting parents of children with developmental delay: a research evaluation. J Mental Defic Res 1991;35:89-112.

33 Elliot C, Smith P, McCulloch K. British Ability Scales, 2nd edn. UK: NFERNelson Publishing Co, 1996.

34 Henderson SE, Sugden DA. Movement Assessment Battery for Children Checklist. The Psychological Corporation, 1992.

35 Achenbach TM. Manual for the Child Behavior Checklist/4-18, YSR, and TRF profiles. Burlington, VT: University of Vermont, Department of Psychiatry, 1991.

36 McCormick MC, McCarton C, Tonascia J, et al. Early educational intervention for very low birth weight infants: results from the Infant Health and Development Program. J Pediatr 1993;123:527-33.

37 Israel C, Dolby S. Parent-Baby Interaction Programme. Windsor: NFER Nelson, 1997.

38 Melnyk BM, Alpert-Gillis L, Feinstein NF, et al. Improving cognitive development of low-birth-weight premature infants with the COPE Program: a pilot study of the benefit of early NICU intervention with mothers. Research in Nursing and Health 2001;24:373-89.

39 Aucott S, Donohue PK, Atkins E, et al. Neurodevelopmental care in the NICU. Mental Retardation and Developmental Disabilities Research Reviews 2002;8:298-308. 